\title{
Tecnologias Sociais, Biopolíticas e Biopoder: Reflexões Críticas
}

\section{Social Technologies, Biopolicies, and Biopower: Critical Reflections}

\author{
Luciano Mendes ${ }^{1}$ \\ Universidade de São Paulo / Escola Superior de Agricultura Luiz de Queiroz (ESALQ/USP), Piracicaba - SP, Brasil \\ Maíra Coelho Bonilha ${ }^{2}$ \\ Universidade Estadual de Maringá / Programa de Pós-graduação em Administração, Maringá - PR, Brasil \\ Elisa Yoshie Ichikawa ${ }^{3}$ \\ Universidade Estadual de Maringá / Centro de Ciências Sociais Aplicadas, Departamento de Administração, Maringá - PR, Brasil \\ Maria Iolanda Sachuk 4 \\ Universidade Estadual de Maringá / Centro de Ciências Sociais e Aplicadas, Departamento de Administração, Maringá, PR, Brasil
}

\section{Resumo}

As tecnologias sociais (TS), como ações que visam a melhorar a qualidade de vida de grupos sociais diversos e que se encontram à margem do mercado ou do sistema econômico, têm por objetivo um novo modelo de desenvolvimento não predatório. Diante da ideia de melhoria da qualidade de vida, essas tecnologias acabam obtendo uma difusão sem limites, colaborando mais para a manutenção do sistema que para a solução definitiva dos problemas sociais. Tendo isso em vista, o objetivo principal deste ensaio teórico é discutir o quanto, muitas vezes, as TS acabam virando panaceia e instrumento das relações de poder, funcionando na justificação e intensificação de novas formas de dominação nas sociedades contemporâneas. Com o intuito de refletir sobre a difusão dessas tecnologias, inicialmente, surgiu a necessidade de aprofundar o entendimento sobre o que são as TS. Em seguida, o intuito foi explorar a visão de Michel Foucault sobre as biopolíticas e o biopoder, e entremear, nessa discussão, as TS.

Palavras-chave: Tecnologias Sociais. Políticas Públicas. Biopolítica. Biopoder.

\section{Abstract}

Social technologies (STs), as actions aimed at improving the quality of life of various social groups that are outside the market or the economic system, aim at a new non-predatory development model. Faced with the idea of improving quality of life, these technologies end up obtaining a diffusion with no limitation, contributing more to the system's maintenance than to the final solution of social problems. Having this in mind, the main objective of this theoretical essay

Artigo submetido em 28 de novembro de 2013 e aceito para publicação em 17 de junho de 2015.

DOI: http://dx.doi.org/10.1590/1679-395113554

${ }^{1}$ Doutor em Administração pela Universidade Federal do Rio Grande do Sul (UFRGS); Professor Associado na USP. Endereço: Avenida Pádua Dias, 11, CEP 13418-900, Piracicaba - SP, Brasil. E-mail: mendes@usp.br

${ }^{2}$ Mestre em Administração pela Universidade Estadual de Maringá (UEM). Endereço: Avenida Colombo, 5790, CEP 87020-900, Maringá - PR, Brasil. E-mail: mabonilha@hotmail.com

${ }^{3}$ Doutora em Engenharia de Produção pela Universidade Federal de Santa Catarina (UFSC). Professora Associada na Universidade Estadual de Maringá. Endereço: Avenida Colombo, 5790, CEP87020-900, Maringá, PR, Brasil. E-mail: eyichikawa@uem.br

${ }^{4}$ Doutora em Administração pela Fundação Getulio Vargas (EAESP/FGV); Professora aposentada da Universidade Estadual de Maringá. Endereço: Rua Neo Alves Martins, 1000 - apto. 1403 - CEP 87050-110, Maringá - PR, Brasil. E-mail: mariaiolanda.sachuk@gmail.com 
is discussing how often STs end up as a panacea and instrument of power relations, working on the justification and intensification of new domination forms in contemporary societies. In order to think through the diffusion of these technologies, first, there emerged the need to deepen understanding of what STs are. Then, the purpose was exploring Michel Foucault's viewpoint on the biopolicies and biopower and interweaving, in this discussion, STs.

Keywords: Social Technologies. Public Policies. Biopolitics. Biopower.

\section{Introdução}

A sociedade contemporânea tem, segundo Foucault (2002), uma estrutura de poder muito diferente daquela que imperou em tempos mais remotos, que se utilizava fundamentalmente da disciplina (como força e imposição) sobre o corpo individual. Hoje, a organização da vida social incide sobre "corpos em multidão", denominada por Foucault (2002) biopolítica - ou seja, a força que regula populações.

Atualmente, as duas formas de poder unem-se, mas de maneira muito sutil. Por um lado, há o poder disciplinar, em que existe a sujeição do corpo às forças que impõem uma relação de docilidade e utilidade (FOUCAULT, 1987); por outro, existe o exercício do poder sobre as populações com sua variante de regularidades e discursos que lhe dão forma e legitimidade. $\mathrm{O}$ aparato científico e a norma acabam sendo os instrumentos mais efetivos de gestão e controle das populações.

Nesse sentido, os discursos sociais de desenvolvimento atuam intensivamente como biopoder. Foucault (2002) estabeleceu o conceito de biopoder para designar o poder de administrar e controlar as populações, e esse poder é colocado em funcionamento, sobretudo, em paralelo à emergência do Estado de bem-estar social.

É importante destacar que em todos os processos nos quais se exerce o biopoder há, concomitantemente, a produção do saber. Assim, a Biologia, a Matemática, a Economia, entre outros campos do conhecimento, são fundamentais quando se precisa de dados demográficos, informações sobre endemias, políticas de natalidade, por exemplo. O biopoder traz, ainda, a criação de novos mecanismos de controle e novas instituições, tais como a seguridade social, os órgãos reguladores, a poupança, e assim por diante.

As políticas sociais de desenvolvimento também são meios de exercer o biopoder e a biopolítica. Elas justificam a ação do sistema capitalista, pois o neoliberalismo tem como base uma biopolítica (BONEFELD, 2013). Logicamente que há variações no tempo e no espaço, dependendo do contexto específico de cada região, mas não há como negar que essas políticas conduzem a processos de socialização e subjetivação dos indivíduos (REVEL, 2013). As ações dessas políticas não são unilaterais, nem determinantes, no sentido de impor regras e obrigações, não intervêm no corpo individual, mas naqueles fenômenos coletivos que podem atingir as populações e afetá-las, como é o caso das políticas públicas para aumentar postos de trabalho, por exemplo (PATTON, 2013).

No caso das políticas relacionadas ao que é atualmente denominado tecnologias sociais (TS), elas visam a promover a inclusão social, e aplicam-se a famílias, cooperativas e associações. O objetivo dessas TS é contribuir para os processos de transformação social, autonomia, inclusão social, visando à melhoria na qualidade de vida da população como um todo (SOFFNER, 2014).

O termo TS passou a ser utilizado em contraposição à tecnologia convencional (TC), que visa a uma forma excludente e exploratória de desenvolvimento no sistema capitalista. A TC estaria engendrada ao sistema industrial de tal forma que os ganhos de capital e a melhoria na qualidade de vida são privilégios de poucos indivíduos. Tendo em vista essa situação, a TS seria uma forma de utilização de conhecimentos, inovações e tecnologias existentes, para a promoção, inclusão e melhor distribuição de renda. Assim, o termo "tecnologias" deve ser compreendido de forma ampla, como o resultado da aplicação de conhecimentos para 
a solução de problemas práticos. Esse conceito genérico de tecnologia permite compreender as TS como inclusivas, emancipatórias, distributivas, e assim por diante (DAGNINO, 2009; GARCIA, 2014).

Apesar da ênfase dada às discussões das TS sobre os aspectos inclusivos, emancipatórios e distributivos, ainda não há mudanças evidentes, e que possibilitem constar na prática e nas ações humanas a centralidade dessas tecnologias. São ações difusas e que, muitas vezes, não atingem o objetivo desejado. Não só porque há uma precariedade no conceito de TS, como salientou Dagnino (2009), que compreende desde a responsabilidade social empresarial até a edificação de uma sociedade socialista, mas, principalmente, porque a aplicação das TS não tem permitido mudanças radicais que alterem a centralidade e difusão das TC (ACSELRAD, 2006).

Diante dessa situação é que alguns questionamentos são importantes: Apesar da difusão das TS nos dias atuais e dos seus pressupostos diferentes das TC, por que as soluções não são permanentes? O que subjaz os discursos sobre as TS que não as colocam como contrárias às TC, mas em situação de paridade? Enfim, por que as TS acabam não logrando resultados plenamente satisfatórios, capazes de alterar políticas e práticas científicas e tecnológicas?

Essas questões conduzem a uma visão mais ampla sobre a existência dos discursos das TS, no sentido de tornar evidente o que, em muitas circunstâncias, está subjugado aos elementos centrais desses discursos e que não produz os resultados idealizados. A empreitada teórica e reflexiva deste artigo não pretende demonstrar uma posição contrária às TS, pois são evidentes as suas contribuições, mas, sim, elucidar as limitações ou falhas na sua adequação, permitindo subsídios para a construção mais apropriada dos elementos centrais dessas tecnologias. Por mais que esse percurso possa incidir na desconstrução dos elementos subjacentes dessas tecnologias, o intuito maior é o seu fortalecimento, principalmente refletindo sobre o lugar-comum que insere as TS no mesmo contexto das TC. Diante dos questionamentos realizados anteriormente, o objetivo deste ensaio teórico é discutir o quanto, muitas vezes, essas TS acabam virando panaceia e instrumento das relações de poder, funcionando na justificação e intensificação de novas formas de dominação nas sociedades contemporâneas.

Assim, este ensaio teórico está organizado da seguinte forma: além desta Introdução, consta uma apresentação do que sejam TS e de que forma elas buscam incentivar o desenvolvimento a partir da inclusão social; em seguida, discute-se os conceitos de biopolítica e biopoder em Foucault para demonstrar o quanto eles servem tanto para a domesticação como para o controle social. Nas Considerações Finais, mostra-se que o discurso das tecnologias é mais um, entre tantos, que embora não traga soluções eficazes para os problemas sociais das populações, é útil para a manutenção e o funcionamento do sistema capitalista.

\section{Explorando os conceitos de tecnologias sociais}

O conceito de TS surgiu da necessidade de uma tecnologia alternativa à TC. O desenvolvimento da ciência e tecnologia (C\&T) nos países capitalistas impulsionou a difusão de tecnologias poupadoras de mão de obra (substituição do trabalho vivo pelo trabalho morto) e focada na maximização dos lucros e na acumulação de capital. Essas TC acabaram impulsionando níveis de desemprego e formas diversas de exploração do trabalho, perpetuando as assimetrias nas relações políticas e sociais (BAUMGARTEN, 2008; NOVAIS e DIAS, 2009; BONILHA e SACHUK, 2011).

As ideias em torno das TS não são recentes. Essas ideias surgiram com as tecnologias apropriadas (TA). A TA foi aplicada na Índia no final do século XIX por Mahatma Gandhi, ao popularizar a fiação realizada em uma roca de fiar (a charkha), por ser uma tecnologia adaptada e capaz de ampliar o trabalho humano e o sustento de um número maior de famílias. Essa ação empreendida por Gandhi diminuiu as injustiças sociais e a dependência do sistema industrial (NOVAIS e DIAS, 2009; BARRETTO e PIAZZALUNGA, 2012). 
Essa perspectiva da TA, compreendida a partir das ações de Gandhi, impulsionou Schumacher (1973) a introduzir o conceito de tecnologias intermediárias (TI), ressaltando a necessidade e o desenvolvimento de tecnologias que tivessem baixo custo, respeito pela dimensão ambiental, fáceis de serem utilizadas e que oferecessem produção em pequena escala. Essas TI seriam a solução para os países subdesenvolvidos, como forma de diminuir os problemas econômicos, sociais e ambientais.

As discussões referentes às TA e TI tiveram grande aceitação, com ações possíveis e diversificadas de inclusão social e participação dos países periféricos no mercado internacional. Apesar da importância e do rápido desenvolvimento desses conceitos, os elementos estruturais do sistema ainda eram mantidos. Assim que surgiu o conceito de TS, a intenção subjacente era que ocorresse uma evolução conceitual em relação aos conceitos de TA e TI, ao mesmo tempo que essas TS proporcionassem o surgimento de uma "outra economia". Isso porque a intenção nas TS era de contribuir com o fortalecimento da economia solidária (ES) e com formas mais colaborativas e integradas da relação do trabalho humano e sustento das famílias. Logo, haveria a necessidade de as TS atingirem três níveis, durante o seu processo de aplicação e desenvolvimento, que seriam: 1) situar as TS como elemento viabilizador da sustentabilidade (econômica, social e ambiental); 2) colocar as TS como fortalecedoras da ES, como alternativas à economia capitalista; e 3) inserir as TS como centrais e articuladoras no contexto da tecnociência (DAGNINO, 2009).

O fato é que o próprio Dagnino (2009) reconhece que nem o primeiro nível foi atingido, no que tange às experiências e ações difusas em relação às TS. Esse fato torna cada vez mais distante as nítidas possibilidades de que os outros níveis possam ser atingidos no médio e longo prazo. Uma das condenações reveladas por Dagnino (2009) é em relação à precarização conceitual, que de uma forma bem sutil causou uma banalização do conceito. Em virtude dessa banalização, Dagnino (2009), que segue a linha marxista, propõe que um conceito genérico de TS seria:

O resultado da ação de um coletivo de produtores sobre um processo de trabalho que, em função de um contexto socioeconômico (que engendra a propriedade coletiva dos meios de produção) e de um acordo social (que legitima o associativismo), os quais ensejam, no ambiente produtivo, um controle (autogestionário) e uma cooperação (de tipo voluntário e participativo), permite uma modificação no produto gerado passível de ser apropriada segundo a decisão do coletivo (DAGNINO, 2009, p. 103).

Apesar desse conceito revolucionário de Dagnino (2009), como o próprio autor havia identificado, as práticas de TS não se desenvolveram, elas não foram capazes de manifestar, por exemplo, a propriedade coletiva dos meios de produção ou mesmo o surgimento das formas de associativismo ou cooperação em todos os empreendimentos referentes às TS. Garcia (2014), ao relatar sobre as definições e os obstáculos referentes às TS, faz uma breve descrição e análise do "Programa Um Milhão de Cisternas no Semiárido" como exemplo efetivo de TS.

A implantação do programa tinha por objetivo a construção, pelas famílias, de cisternas feitas com placas de concreto, para captação e armazenamento de água das calhas nos períodos de precipitação. Garcia (2014) comenta que a construção das cisternas possibilitou um processo participativo mesmo antes dessa construção, maior proximidade dessas famílias com os órgãos governamentais (estadual e municipal), e a conscientização dessas pessoas sobre os problemas do semiárido. Foram feitos diversos treinamentos (dos membros das famílias) para fabricação e construção das cisternas. O fato é que essas TS só foram possíveis por meio das intervenções do Estado brasileiro. Quando, em 2011, o programa entrou em crise por falta de recursos, ocorreu uma mudança geral. $\mathrm{O}$ governo federal deixou de dispender recursos para as ações de integração (família e órgãos governamentais) e treinamento, passando a comprar as cisternas de plástico das indústrias. Diante desse panorama, Garcia (2014, p. 34) conceitua TS como: 
[...] mais um exemplo das perspectivas alternativas que vêm contribuindo substancialmente para um entendimento mais adequado à complexidade dos processos sociais e naturais, projetando modelos de ação capazes de produzir efeitos benéficos em diversas dimensões (cognitiva, econômica, social, cultural e ambiental), reveladores das possibilidades históricas de realização dos ideais modernos de igualdade e liberdade universais e de um modo de vida no qual a razão se articula com a justiça social e o florescimento humano.

Apesar de Garcia (2014) realizar uma ampla digressão sobre a perspectiva de TS empregada por Renato Dagnino, ainda há diferenças substanciais entre os conceitos de Garcia e Dagnino. Garcia (2014) retoma a ideia de perspectiva alternativa e não perspectiva revolucionária, que subjaz o conceito de Dagnino (2009). Além disso, por Garcia (2014) expor a definição de TS por meio de um sujeito indeterminado provavelmente porque a ação exemplificada foi realizada por um programa governamental, as TS concebidas como resultado de um coletivo de produtores sobre um processo de trabalho não surgiu como algo central no conceito. E, por fim, especificamente em relação ao exemplo apresentado por Garcia (2014), fica evidente não a emancipação, mas a dependência das famílias do semiárido das ações e programas do Estado, onde uma mudança circunstancial (por exemplo, recursos limitados) pode produzir um retorno rápido às TC. Novamente, como salientou Dagnino (2009), nem o nível da sustentabilidade tem sido atingido nas ações em TS.

Utilizando o caso apresentado por Garcia (2014), é possível dizer que as famílias que construíram suas cisternas, antes da crise do programa, conseguiram diminuir a sua dependência do Estado e, portanto, as TS foram efetivas para aquele grupo de pessoas. O fato é que, ao evidenciar as TS como evolução das TA e TI, no sentido de que o conceito de TS passou a dar conta das limitações existentes naqueles conceitos, ao mesmo tempo que manteve seus atributos importantes para atingir a inclusão social, as TS expressas no exemplo de Garcia (2014) deveriam ser amplamente difundidas para outras famílias (mesmo que de uma família para outra) e os recursos utilizados deveriam ser menores que aqueles das TC. A difusão entre famílias (expressa no conceito de TA) e a economia de recursos em relação à TC (expressa na TI) estão subjacentes ao conceito empregado por Dagnino (2009), mas que, na prática, ou melhor, no caso do "Programa Um Milhão de Cisternas no Semiárido", não estão evidentes.

Freitas e Segatto (2014) ao discutirem a proposta das TS, tendo como base a Teoria Crítica da Tecnologia, possibilitam algumas constatações. Inicialmente em relação aos princípios da TS que são: aprendizagem e participação como processos integrados; transformação social por meio da compreensão sistêmica da realidade; transformação social com respeito às identidades locais; e a capacidade dos indivíduos de apreender e gerar/disseminar/compartilhar tecnologias. Mais tarde, esses autores definem os parâmetros das TS, evidenciando, por exemplo, as razões de ser, o papel da população, a construção do conhecimento etc. Finalmente, em uma perspectiva de adaptação sociotécnica, os autores elucidam as modalidades de adequação das TS, como: uso, apropriação, ajuste no processo de trabalho, incorporação do conhecimento científico-tecnológico etc. Com essas constatações, Freitas e Segatto (2014) concluem que as TS estão de acordo com a Teoria Crítica da Tecnologia, que expõe a necessidade das tecnologias serem mais democráticas e avessas às formas de produção das TC.

Apesar de os estudiosos (DAGNINO, 2009; NOVAIS e DIAS, 2009; GARCIA, 2014) salientarem os diferenciais entre as TS e as TC, os problemas inerentes a essas perspectivas vão além da simples elucidação de suas oposições. O problema subjaz o termo tecnologia, enredado no contexto da ciência, tecnologia e sociedade (CTS). E não é simplesmente enfatizar o lado humano ou não da tecnologia, assim como a necessidade de aproximação ou não entre a ciência, a tecnologia e a sociedade, evidente em muitos trabalhos que discutem as TS (DAGNINO, BRANDÃO e NOVAES, 2004; RODRIGUES e BARBIERI, 2008; ANDRADE, CORDEIRO NETO e VALADÃO, 2013). O fato primordial é entender questões do tipo: tecnologias para quê e para quem? Tecnologias inclusivas ou mesmo sociais para que e para quem? Quais as intenções subjacentes às TC e TS? 
Que as TS possibilitam suporte e melhorias significativas na vida dos indivíduos não há como negar, pois muitos estudos (LASSANCE JUNIOR, 2004; RODRIGUES e BARBIERI, 2008; COSTA, 2013) comprovam e dão subsídios a essas afirmações. Entretanto, é necessário ir além. O trabalho de Mueller e Ferraz (2013) proporciona uma série de constatações sobre as TS. A partir de um construção teórica referenciada em Marx e Lukács, estes autores derrubam o possível antagonismo existente entre as TC e as TS, salientado que ambas estão enredadas a uma circunstância social e econômica, que possibilita a organização, controle e possíveis resultados a serem atingidos. Além disso, Mueller e Ferraz (2013) consideram que há limitações na apropriação, feita por Dagnino (2009), de que as TS são libertadoras e autogestionárias, pois, ao focar a TC como fator alienante, Dagnino (2009) esquece que não é a tecnologia, mas os modos de produção capitalista que são alienantes. Se não existe contestação desses modos de produção capitalista, então, as tecnologias "sociais" nunca serão emancipatórias ou autogestionárias.

Os argumentos elucidados no trabalho de Mueller e Ferraz (2013) permitem desconstruções importantes sobre o contexto e as formas de apropriação das TS, que não levam à emancipação ou mudança radical na vida dos indivíduos, pois o contexto de produção e disseminação dessas tecnologias é o mesmo das TC. Esses argumentos dão conta de muitos dos questionamentos feitos anteriormente, mas é necessário ir além e contribuir com essa discussão. Assim, sem se ater às considerações de Marx e Lukács, que foi o empreendimento de Muller e Ferraz (2013), as reflexões realizadas por Michel Foucault é que serão trabalhadas neste ensaio teórico. Isso porque Michel Foucault possibilitou reflexões importantes sobre os pressupostos subjacentes ao capitalismo, nas considerações dos neoliberalistas, e da centralidade da vida na dimensão política e tecnológica da sociedade dos últimos anos. As relações entre as TS e as reflexões foucaultianas serão abordadas e exploradas no próximo tópico.

\section{A biopolítica e o biopoder evidentes nos discursos sobre as tecnologias sociais}

Tendo em vista a discussão anterior sobre as TS, não há como negar a sua importância no contexto atual, dado o fato de que no entremeio ao sistema em que vivemos as precarizações em relação à vida ainda continuam acentuadas. Procurar estratégias que deem conta de solucionar grande parte dos problemas sociais torna-se um fator fundamental. Entretanto, até que ponto essas estratégias atingem seus objetivos de solucionar problemas?

Foucault (2008) analisa detidamente o desenvolvimento do sistema capitalista e, em particular, o surgimento de uma perspectiva econômica que ficou conhecida como neoliberalismo. Sem adentrar, aqui, especificamente essa temática, Foucault (2008) diz que o neoliberalismo se diferencia em vários fatores do liberalismo elucidado no trabalho de Adam Smith, pois a lógica já não é mais a de saber se no interior da sociedade era possível arranjar um espaço livre que seria o mercado, mas, sim, saber se seria possível, no interior de uma economia de mercado, regular um exercício global do poder político. Foucault (2008) analisa três temáticas centrais nessa visão neoliberalista, que seriam: o monopólio, a regulamentação (ou ação econômica conforme) e as políticas sociais. A partir desse contexto, Foucault (2008) desenvolve sobre a política social nesse contexto neoliberal torna-se interessante nesse ponto.

Por qual caminho a política social se entremeia nessa visão neoliberalista? A política social vai em direção ao que é considerado o grande problema do sistema capitalista: o desemprego. Apesar de ser um problema, Foucault (2008) mostra que na visão neoliberalista - particularmente no trabalho de Wilhelm Röpke - o desempregado não é um deficiente econômico, assim como não é vítima da sociedade, mas somente um trabalhador em trânsito, ou seja, um trabalhador em busca de uma atividade mais rentável daquela que exercia anteriormente. Entretanto, se o desemprego tornar-se um problema acentuado, como resolvê-lo? Essa é uma questão interessante, pois na visão neoliberalista, os investimentos não devem ser feitos nos preços dos produtos, nem nos setores considerados deficitários, pois essas são intervenções ruins, mas na população. Se há problemas, por exemplo, de excesso de trabalhadores agrícolas, salienta Foucault (2008), então é 
necessário impulsionar a migração, assim como se os problemas estão relacionados às técnicas ou ferramentas, nesse caso, é importante investir na formação dos agricultores, colocar à disposição mais ferramentas, rever as técnicas. Somente dessa forma os problemas em uma economia de mercado poderiam ser solucionados.

Esse tipo de intervenção não incide sobre os elementos econômicos, muito menos sobre os mecanismos específicos de mercado, mas sobre a população, as técnicas, a aprendizagem e a educação. Nesse ponto, Foucault (2008, p.193) diz que:

A ideia não era: dado o estado de coisas, como encontrar o sistema econômico capaz de levar em conta os dados básicos próprios da agricultura europeia? Mas sim: dado que o processo de regulação econômico-político, como modificar essas bases materiais, culturais, técnicas, jurídicas que estão dadas na Europa? Como modificar esses dados, como modificar essa moldura para que a economia de mercado intervenha? E vocês veem aí uma coisa sobre [a qual] tomarei daqui a pouco: que, afinal, tanto a intervenção governamental deve ser discreta no nível dos processos econômicos propriamente ditos, como, ao contrário, deve ser maciça quando se trata desse conjunto de dados técnicos, científicos, jurídicos, demográficos, digamos, grosso modo, sociais, que vão tornar-se agora cada vez mais o objeto de intervenção governamental.

Essa incursão inicial sobre o tema do neoliberalismo e sobre o problema social do desemprego mostra que as TS não se constituem como alternativa aos problemas que surgiram com o sistema capitalista e com as influências dos neoliberalistas, mas, simplesmente, se encaixam perfeitamente à lógica subjacente para a sustentação e manutenção desse sistema. Se o problema é o desemprego, como salienta Foucault (2006), então, é necessário impulsionar esse excesso de contingente econômico para outras atividades que, não necessariamente, vão dar conta dos problemas, mas apenas - na forma de intervenção discreta - irão conduzir a uma aparente solução, que surge em nossa sociedade a partir de uma série de nomes como, por exemplo, o de TS.

Essa primeira constatação extraída do texto Foucault (2008) já permite algumas reflexões sobre as TS e corrobora com o evidenciado no trabalho de Mueller e Ferraz (2013) sobre o fato de as TS não serem revolucionárias em sua gênese e muito menos avessas às TC, pois essas TS ampliam a sustentação do sistema e a manutenção das desigualdades. Nesse sentido, tais TS, como pôde ser evidenciado nos trabalhos de Dagnino (2008; 2009), apesar de permitirem melhorias na situação de vida dos indivíduos, em longo prazo, causam manutenções em sua estrutura, além de gerar maior dependência em relação às políticas públicas, como foi possível observar no trabalho de Garcia (2014).

Foucault (2006) não é contra essas iniciativas, que têm contribuído muito com um grande número de pessoas. É necessário ressaltar nesse percurso sobre o trabalho de Foucault (2008) que o discurso sobre as TS não se encaixa como discurso alternativo, muito menos - como ressaltaram Dagnino (2009) e Garcia (2014) - de outra natureza e conceituação, mas como discurso que pode ser encontrado nas primeiras iniciativas dos economistas neoliberais. Mais adiante, as considerações de Foucault (2008) mostram que as discussões sobre TS não são avessas e muito menos contrárias aos discursos neoliberais.

Foucault (2008) coloca que o neoliberalismo surge de forma diferenciada na Alemanha, na França e nos Estados Unidos, imperando neste último, dada a forma como foi conduzido. Se os problemas do desemprego, da miséria, das políticas sociais, entre outros, foram há muito tempo problemas que elucidaram questionamentos acirrados sobre as mazelas do sistema capitalista, no contexto dos neoliberais tais problemas deveriam ser enfrentados ou, em partes, amenizados. Após um longo período de influência e sustentação das políticas - denominadas por Foucault (2008) - não liberais, que eram as políticas 
intervencionistas, políticas keynesianas e políticas sociais, seria estrangulador para o sistema que muitas dessas ações fossem abandonadas ou mesmo eliminadas em favor dos ditames do mercado.

O que Foucault (2008) procura mostrar é que o surgimento do neoliberalismo - principalmente o praticado nos Estados Unidos - teve que dar conta desses vários problemas, por meio de estratégias múltiplas. Uma primeira estratégia evidente nos discursos do neoliberalismo foi a produção e multiplicação do que Foucault (2008) denominou "empresa" "Não apenas as organizações lucrativas passariam a ser consideradas empresas, mas, também, as não lucrativas, assim como todas as pessoas que oferecem sua força de trabalho no mercado.

Nesse ponto, Foucault (2006) faz uma observação importante. Durante muitos anos os economistas clássicos ou neoclássicos salientavam que os fatores econômicos eram: terra, capital e trabalho. Apesar de considerar o trabalho como fator econômico, nenhum economista clássico ou neoclássico se deteve especificamente sobre o que realmente é o trabalho. Depois de Adam Smith, salienta Foucault (2002), que considerava o trabalho, ou melhor, o tempo de trabalho um denominador para expressar o valor das mercadorias, nenhum economista clássico ou neoclássico foi capaz de desenvolver uma teoria fundamentada sobre o trabalho, ficando essa categoria vista somente a partir do seu tempo de uso. Foucault (2002) mostra que o trabalho está além do tempo, assim como não é um fator de troca, ou seja, o trabalhador não visualiza o salário como recompensa pelo trabalho exercido, mas como possibilidade de consumo. Assim como, se o trabalho foi renegado ao fator tempo, então, apenas alguns atributos qualitativos compõem o que se espera do trabalhador, que está vinculado a sua competência. Nessa visão de que o trabalho é considerado a partir do seu tempo de execução e de que a busca, durante esse tempo de execução, seria pela eficiência e eficácia do trabalho executado, o foco principal estaria vinculado sobre aquilo que Foucault (2008) denominou competência.

A competência na execução do trabalho e a ideia de propagação de formas diversas de "empresas" constituíram a base do que os economistas na década de 1970 denominaram "capital humano". Nesse arcabouço teórico, Foucault (2008) mostra que a intenção maior foi a de permitir certa concorrência de mercado no que tange à mão de obra disponível, assim como a obrigação (ou responsabilidade) pelo desempenho satisfatório, ou não, fosse de responsabilidade dessas microunidades de empresas que constituíam o que os economistas denominavam exército de reserva. Entretanto, como dar conta do problema social do desemprego em uma economia neoliberalista? E Foucault (2008) diz que toda essa mudança que se institui sobre os denominadores tempo/trabalho/competência acabou por impulsionar formas diversas de "aproveitamento" das "empresas" (principalmente a casta pobre da sociedade) por meio daquilo que seriam suas competências. Se o mercado formal em si não fosse capaz de absorver esse excesso de contingente, então, seria necessário impulsionar atividades alternativas, capazes de produzir o sustento mínimo - e assim disciplinado - desse grande número de pessoas. Isso fica claro na seguinte passagem:

Quando se tem homens em grande número que podem subsistir e que gozam de boa saúde, é necessário zelar por sua atividade. Por sua atividade, entender, antes de mais nada, o fato de que não fiquem ociosos. Pôr para trabalhar todos os que podem trabalhar é a política voltada para os pobres válidos. Prover unicamente as necessidades dos pobres inválidos. E será também, muito mais importante, zelar pelos diferentes tipos de atividade de que os homens são capazes, zelar para que, efetivamente, os diferentes ofícios de que se necessita, de que o Estado necessita, sejam efetivamente praticados, zelar para que os produtos sejam fabricados de acordo com um modelo que seja tal que o país possa se beneficiar (FOUCAULT, 2008, p.436).

\footnotetext{
${ }^{5}$ Nesse caso, o termo mais bem empregado seria firma, pois Foucault (2008) realiza uma análise sobre escritos de economistas, mas na tradução para o português consta empresa.
} 
O que Foucault (2008) expressa neste parágrafo está diretamente ligado à deficiência do sistema econômico defendido pelos neoliberalistas, por meio da busca de alternativas que amenizem os problemas, mas não, necessariamente, os resolvam. Por essa análise, o que fica claro é uma associação direta com o foco das TS, destinadas à casta pobre da sociedade e que não possui acesso ou mesmo se encontra à margem do mercado. Portanto, é necessário tornar esses sujeitos - que gozam de uma boa saúde - em empresas individuais, aptos a produzir e obter o mínimo de renda para os seus sustentos. Assim, o discurso das TS impulsiona os sujeitos a tomarem consciência de que os problemas não são inerentes ao sistema econômico, mas que estão diretamente associados às dificuldades que tais sujeitos possuem de desenvolver e manifestar suas próprias competências. Se há problemas no sistema, isso se deve mais aos sujeitos integrantes do que necessariamente aos malefícios causados e produzidos no capitalismo. Dessa forma, uma segunda constatação torna-se evidente, que é o fato de que a existência dos discursos sobre TS não somente causam a manutenção e possibilitam a disciplina de uma parcela da população, mas, principalmente, reforçam e coadunem com os princípios neoliberais (MUNRO, 2012).

As TS, na linha exposta por Foucault (2006), não se encaixam em um novo e revolucionário conceito, como expôs Dagnino (2009), pois há muito o foco de atuação no discurso das TS já foi exposto pelos economistas neoclássicos, ou seja, dar conta dos problemas sociais sem recorrer a um discurso socialista de cunho marxista. Essa tentativa de distanciamento dos discursos marxistas acabou impulsionando e instaurando o que Foucault (2008) denominou surgimento de variadas "empresas", da necessidade e manifestação de competências que vão além daquelas exigidas no mercado formal, das diversas estratégias de sobrevivências que colocam o sujeito como o principal produtor e reprodutor da sua situação de vida, do surgimento de estratégias e tecnologias capazes de garantir o mínimo em termos de recursos. O discurso sobre as TS que evidenciam tais tecnologias, por exemplo, a partir de "um entendimento mais adequado à complexidade dos processos sociais e naturais, projetando modelos de ação capazes de produzir efeitos benéficos em diversas dimensões" (GARCIA, 2014, p. 34), está totalmente condizente com a perspectiva neoliberal, no que diz respeito às "manifestações das competências", às "estratégias de sobrevivências" etc.(SPRINGER, 2012).

Contudo, não é apenas isso. Fica evidente também, nas discussões sobre as TS, um imperativo das ideias neoliberais. Paulatinamente, salienta Foucault (2008), os neoliberais foram absorvendo os problemas sociais, sem impor ao Estado obrigações constantes em termos de investimentos em determinadas políticas públicas. Por exemplo, as discussões sobre o trabalho - e com isso o desemprego - foram instituídas pelos neoliberais em uma perspectiva avessa à de Marx. Enquanto no texto de Marx, observa Foucault (2008), o questionamento central era sobre o que significava o trabalho para o sistema capitalista, nas considerações dos neoliberais americanos a indagação inverte-se e o questionamento é sobre o significado do trabalho para o trabalhador.

A constatação que chegam os neoliberais é de que o trabalho para o trabalhador significa obtenção de renda, que irá impactar na sua situação de vida. É partir da mudança sobre o significado do trabalho que conceitos como "empresas", "competências" etc., tornam-se fundamentais na evasão da ideia de que os problemas sociais são inerentes ao sistema capitalista, impulsionando esses problemas para o próprio trabalhador. Nessa linha, o desemprego passa a significar não mais a incapacidade do sistema capitalista em chegar à situação de pleno emprego, mas a fatores como "incompetência" e" ingerência da situação de vida", em que a culpa decai sobre o próprio trabalhador (BINKLEY, 2014).

O que esta discussão sobre o trabalho tem a ver com as TS? Primeiro, como já salientado, é a inversão de perspectiva, já denunciada por Mueller e Ferraz (2013), de que determinados problemas sociais são gerados pelas formas de aplicação das tecnologias (no caso as TC) e não por ineficiências do sistema (GRINT e WOOLGAR, 2013). Segundo é que os discursos sobre as TS, em suas diversas derivações, acabaram acompanhando a lógica dos discursos neoliberais quando focam, por exemplo, a necessidade de autonomia e autogestão nos empreendimentos, excetuando muito das obrigações do Estado (VARGA, 2013). Terceiro é a introdução de que os problemas sociais sendo inerentes às tecnologias, qualquer ação diferente das TC 
proporciona possíveis resultados, causando menor contestação em relação às políticas públicas e às possíveis ineficiências na sua aplicação (LIPPERT, 2014).

Todas essas mudanças, salienta Foucault (2006), estão diretamente associadas às estratégias instituídas a partir dos discursos dos economistas neoliberais que, de uma forma ou de outra, foram adequando-se e acomodando-se ao sistema, funcionando não somente como sistema econômico em si, mas, também, político. Com essa evidência, Foucault (2008) questiona: o que possibilitou a sustentação dessas mudanças de ideias que foram surgindo no século XX e que estão presentes nos discursos dos economistas neoliberais?

Foucault (2008) responde que essa pergunta está assentada em uma nova forma de fazer e realizar a política que, além de gerar a disciplina, foi capaz de sustentar as ações econômicas. Isso só foi possível quando a política penetrou no último e mais sublime fenômeno da manifestação humana: a vida. Na visão de Foucault (2006), as mudanças e sustentações dos processos econômicos e políticos (sentido estrito) só foram possíveis a partir do momento que passaram a ser processos que incidiam sobre a vida. O controle, a disciplina, a ordem contida, as ineficiências do sistema, entre tantas outras críticas que poderiam ser elucidadas segundo as mazelas do sistema capitalista, só foram resolvidas, amenizadas ou mesmo contidas, a partir de um discurso sobre a vida.

Para chegar a essa afirmação, Foucault (2006) percorre uma série de textos políticos que foram escritos desde o século XVII até meados do século XX. Entre esses textos estão os de Maquiavel, Hobbes, Rousseau, até textos de autores menos conhecidos e que os tiveram publicados antes e depois da virada do século XIX. Sem querer adentrar a densidade, a amplitude e a complexidade dessa análise feita por Foucault (2006), pois isso tomaria tempo significativo neste ensaio, esse historiador das ideias constata uma divisão nítida entre os escritos anteriores e posteriores ao século XVIII, que possuem como divisor de águas a obra de Maquiavel.

Procurando resumir essa divisão, Foucault (1988) salienta que antes do século XVIII uma frase que representaria muito bem as intenções contidas nos escritos de Maquiavel seria: "fazer morrer e deixar viver". Com esta frase, Foucault (1988) diz que o príncipe já possuía um poder sobre a vida dos seus súditos, mas de que esse poder - muito associado à força física - se revelava a partir da capacidade de matar. $\mathrm{O}$ controle social era um controle estabelecido a partir da morte, o que não tardou para gerar focos de revolta e rebelião contra os sistemas de principados. Nessa época, virada do século XVIII, começa a surgir uma literatura antiMaquiavel, que acaba por inverter toda lógica da análise de Maquiavel. A partir dessa literatura, Foucault (1988) evidencia o surgimento da lógica do "fazer viver e deixar morrer" em detrimento do "fazer morrer e deixar viver". Isso porque a literatura anti-Maquiavel procurou focar no gerenciamento da coisa pública, na melhor forma de aperfeiçoar a situação de vida das pessoas, no controle da natalidade, das doenças e da mortalidade, na necessidade constante de "fazer viver". Foucault (1988, p.131) diz:

A velha potência da morte em que se simbolizava o poder soberano é agora, cuidadosamente, recoberta pela administração dos corpos e pela gestão calculista da vida. Desenvolvimento rápido, no decorrer da época clássica, das disciplinas diversas - escolas, colégios, casernas, ateliês; aparecimento, também, no terreno das práticas políticas e observações econômicas, dos problemas de natalidade, longevidade, saúde pública, habitação e migração; explosão, portanto, de técnicas diversas e numerosas para obter a sujeição dos corpos e o controle das populações. Abre-se assim a era do "biopoder" e da "biopolítica".

Na visão de Foucault (1988), essa nova tecnologia só foi possível com o surgimento da estatística, que permitiu análises mais abrangentes sobre a situação da população. O foco dessas análises estatísticas esteve assentado sobre as diversas taxas (natalidade, longevidade, mortalidade etc.), mas, também, sobre a forma, a natureza, a extensão e a duração das doenças. Isso porque, salienta Foucault (1988), as endemias e epidemias causam problemas sociais graves para o sistema capitalista, pois subtraem as forças, diminuem o tempo de 
trabalho, causam baixa de energia e geram, automaticamente, custos econômicos. O "fazer viver" está assentado na utilidade da população para o sistema, assim como o "deixar morrer" está vinculado à despreocupação com uma casta dessa população incapacitada de gerar benefícios sociais e econômicos.

Nesse ponto, a biopolítica articula-se aos preceitos do neoliberalismo, no sentido de que o "fazer viver" está endereçado à população economicamente ativa (WACQUANT, 2012). Assim, as TS integram também a biopolítica, pois enfatizam as melhorias na qualidade de vida e a busca constante de integração de uma parcela da população economicamente ativa ao mercado. Esse foco fica visível, por exemplo, no trabalho de Lopes, Borba, Trajber et al. (2011), que estudaram oficinas de atividades com jovens que estão em situação de vulnerabilidade social como forma de TS. Assim como o trabalho de Silva e Alencar (2014) que compreenderam o "banheiro seco" como TS capaz de melhorar a higiene e o tratamento de dejetos humanos em uma comunidade rural de São Luís, Maranhão. Também o trabalho de Garcia (2014), que enfatizou o "Programa Um Milhão de Cisternas no Semiárido" como iniciativa compatível aos preceitos das TS.

Tais exemplos enfatizam o desenvolvimento rápido da biopolítica, como controle amplo das situações de vida das populações. As iniciativas em TS são sempre em séries e difusas, não comportando soluções efetivas na qualidade de vida das populações. São programas ou ações micro e endereçadas à solução de problemas tópicos e específicos, que têm o papel de contribuir com uma parcela muito pequena dos problemas enfrentados por grande parte da população, enquanto outros problemas continuam limitando soluções efetivas. Essa biopolítica, conforme observa Foucault (1988), torna-se também um biopoder, que disciplina e controla uma parcela da população, evitando transgressões, ao mesmo tempo que sustenta e mantém as ineficiências do sistema capitalista.

É nessa situação que as TS surgem como soluções paliativas para uma casta da população que possui ou goza de boa saúde, mas se encontra à margem (ou mesmo excluída) do sistema. A integração e o discurso promovido pela necessidade de gerar TS têm valor por ser capazes de extrair benefícios para o sistema. Por esse motivo, nesses discursos, operam termos como "tecnologias alternativas" (DAGNINO, 2008), "metodologias transformadoras" (CRISTOFIDIS, 2006), "tecnologias inovadoras" (GUSHIKEN, 2004), "novas ideias" (FRITZEN, PIETSCH, FREITAS et al., 2008), "transformação social" (FREITAS e SEGATTO, 2014), "justiça social”(GARCIA, 2014), entre outros. O intuito é o de integrar, mesmo que à margem, um grupo social aos ditames e processos de mercado.

Não há como negar os benefícios sociais desse processo em um sistema capitalista. O fato é que, mesmo idealizando esses benefícios, essa casta da população continua marginalizada e nunca integrará amplamente o sistema. Foucault (1988) elucida esse fato, ao dizer que a biopolítica e o biopoder constituem formas atuais, mais de controles sociais, que necessariamente geradoras de benefícios sociais. Integrar uma parte da população, ainda marginalizada socialmente, em ações, é uma forma de sustentar a não rebelião social, gerando aquilo que Foucault (1987) denominou "corpos dóceis" e "disciplinados".

Como bem expõem Rodrigues e Barbieri (2008), as TS têm o objetivo de atender as populações mais carentes em termos de água, alimentação, educação, energia, habilitação, renda, saúde e meio ambiente. O fato é que, salienta Foucault (2008), essas iniciativas não geram soluções eficazes e muito menos intentam dar conta de todos os problemas. Soluções paliativas e tópicas são permanentemente exigidas e implementadas, mas não conseguem proporcionar respostas conclusivas e contínuas, como foi possível observar no trabalho de Garcia (2014). Os objetivos diante dessas ações, salienta Foucault (2008), têm a intenção de reduzir custos que resolver os problemas sociais; têm a intenção de gerar "corpos dóceis" que resolver completamente os problemas. Com isso, as TS integram esse discurso moderno do "fazer viver e deixar morrer", como tecnologias úteis para a manutenção e o funcionamento do sistema capitalista. 


\section{Considerações finais}

Este ensaio discute o quanto, muitas vezes, as TS acabam virando panaceia e instrumento das relações de poder, funcionando na justificação e intensificação de novas formas de dominação nas sociedades contemporâneas. Para conduzir as reflexões instituídas neste ensaio teórico, alguns questionamentos foram norteadores, são eles: Apesar da difusão das TS nos dias atuais e dos seus pressupostos diferentes das TC, por que motivos as soluções não são permanentes? O que subjaz os discursos sobre as TS que não as colocam como contrárias às TC, mas em situação de paridade? Enfim, por que motivos as TS acabam não logrando resultados amplamente satisfatórios capazes de alterar políticas e práticas científicas e tecnológicas?

Como são questões norteadoras, as respostas podem ser diversas e estão relacionadas às intenções neste ensaio. Por esse motivo, a busca por respostas foi baseada na perspectiva teórica de Michel Foucault, particularmente em suas discussões sobre o neoliberalismo americano e as ideias sobre a biopolítica e o biopoder. Utilizando como foco as discussões e ações em TS, foi possível evidenciar, a partir da perspectiva foucaultiana, que as TS não são avessas aos pressupostos do sistema capitalista e das TC, mas estão confortavelmente posicionadas na manutenção dos pressupostos que fortalecem e marginalizam parte da população. As TS, ao ser utilizadas de forma seriada e tópica, não produzem alterações que solucionam os problemas mais gerais, e quando geram soluções, estas favorecem o sistema.

Com já foi salientado, Foucault (2008) não é contra os benefícios gerados pelas tentativas de ações desse tipo, mesmo que paliativos. O fato é que, essa visão condiciona a lógica do "algo está sendo feito", mesmo não gerando solução ou resolução do problema. E é justamente nessa perspectiva do "algo está sendo feito" que a disciplina e a docilidade dos corpos são evidentes, pois, qualquer forma de reflexão sobre os problemas sociais e a maneira como esses problemas estão sendo tratados ou solucionados, pode incitar pontos e focos de aversões.

Essas aversões estão no fato de se acreditar que a reflexão tem a intenção de desconsiderar ou mesmo de criticar essas ações consideradas positivas. A intenção, aqui, é totalmente outra, pois acredita-se que ao elucidar os problemas inerentes a essas ações paliativas, procurando dar destaque ao que subjaz tais ações, é a maneira mais efetiva de se pensar, por exemplo, em formas de continuidade, de resolução dos problemas e, quem sabe, de transgredir a lógica que constitui esse tipo de política pública. Evidenciar, por exemplo, que os discursos sobre as TS possuem sua lógica ligada aos pressupostos de funcionamento do sistema capitalista e, por isso, não são ações que transcendem a continuidade das coisas como estão, é a forma mais prudente de visualizar possíveis melhorias, possíveis mudanças ou possíveis ações que promovam resultados mais efetivos e condizentes.

\section{Referências}

ACSELRAD, H. Tecnologias sociais e sistemas locais de poluição. Horizontes Antropológicos, v. 12, n. 25, p. 117$138,2006$.

ANDRADE, J. A.; CORDEIRO NETO, J. R.; VALADÃO, J. A. D. Associações sociotécnicas e práticas de gestão em desenvolvimento: analisando rastros por entre o traçado do P1MC. Cad. EBAPE.BR, v. 11, n. 2, p. 274-294, 2013.

BARRETTO, S. F. A.; PIAZZALUNGA, R. Tecnologias sociais. Ciência e Cultura, v. 64, n. 4, p. 4-5, 2012.

BAUMGARTEN, M. Ciência, tecnologia e desenvolvimento-redes e inovação social. Parcerias Estratégicas, v. 26, p. 101-123, 2008. 
BINKLEY, S. Happiness as enterprise: an essay on neoliberal life. New York: State University of New York Press, 2014.

BONEFELD, W. Human economy and social policy On ordo-liberalism and political authority. History of the Human Sciences, v. 26, n. 2, p. 106-125, 2013.

BONILHA, M. C.; SACHUK, M. I. Identidade e tecnologia social: um estudo junto às artesãs da Vila Rural Esperança. Cad. EBAPE.BR, v. 9, n. 2, p. 415-437, 2011.

COSTA, A. B. (Org.). Tecnologia social e políticas públicas. São Paulo: Instituto Pólis, 2013.

CRISTOFIDIS, M. O enquadramento participativo de corpos d'água como um instrumento da gestão de recursos hídricos com aplicação na bacia do Rio Cubatão Sul - SC. Dissertação (Mestrado) - Programa de Pós-Graduação em Engenharia Ambiental, Universidade Federal de Santa Catarina, Florianópolis 2006.

DAGNINO, R. P. Tecnologia social é inédita e revolucionária. Disponível em: <http://www.rts.org.br/ noticias/forum_RTS/tecnologia-social-e-inedita-e-revolucionaria>. Acesso em: 26 out. 2008.

DAGNinO, R. P. Introdução. In: DAGNINO, R. Tecnologia social: ferramenta para construir outra sociedade. Campinas, SP: Unicamp, 2009. 5-16 p.

DAGNINO, R. P.; BRANDÃO, F. C.; NOVAES, H. T. Sobre o marco analítico-conceitual da tecnologia social. In: LASSANCE JUNIOR, A. E. A. (Org.). Tecnologia social: uma estratégia para o desenvolvimento. Brasília, DF: Fundação Banco do Brasil, 2004. 216 p.

FOUCAULT, M. A governamentalidade. In: FOUCAULT, M. Microfísica do poder. 3. ed. Rio de Janeiro: Graal, 1982. $432 \mathrm{p}$.

FOUCAULT, M. Vigiar e punir: história da violência nas prisões. 28. ed. Petrópolis, RJ: Vozes, 1987.

FOUCAULT, M. História da sexualidade: a vontade de saber. Rio de Janeiro: Graal, 1988. v. 1.

FOUCAULT, M. A verdade e as formas jurídicas. Rio de Janeiro: Nau, 1996.

FOUCAULT, M. As palavras e as coisas: uma arqueologia das ciências humanas. São Paulo: Martins Fontes, 1999.

FOUCAUlT, M. Em defesa da sociedade. Curso no Collège de France (1974-1975). São Paulo: Martins Fontes, 2002.

FOUCAULT, M. A tecnologia política dos indivíduos. In: FOUCAULT, M. Ética, sexualidade e política: ditos e escritos. v. 3. ed. Rio de Janeiro: Graal, 2006. 392 p.

FOUCAULT, M. O nascimento da biopolítica: curso no Collège de France (1978-1979). São Paulo: Martins Fontes, 2008.

FREITAS, C. C. G.; SEGATTO, A. P. Ciência, tecnologia e sociedade pelo olhar da tecnologia social: um estudo a partir da Teoria Crítica da Tecnologia. Cad. EBAPE.BR, v. 12, n. 2, p. 302-320, 2014.

FRITZEN, É. N. et al. Capital social e educação ambiental: ferramentas de tecnologia social para educadores do Ensino Fundamental e Médio no Paraná. In: PEIXE, B. C. S. et al. (Org.). Gestão de políticas públicas no Paraná: coletânea de estudos. Curitiba: Progressiva, 2008. 516 p.

GARCIA, S. G. A tecnologia social como alternativa para a reorientação da economia. Estudos Avançados, v. 28 , n. 82, p. 251-275, 2014.

GRINT, K.; WOOLGAR, S. The machine at work: technology, work and organization. New York: John Wiley \& Sons, 2013. 
GUSHIKEN, L. Introdução. In: LASSANCE JUNIOR, A. E. A. (Org.). Tecnologia social: uma estratégia para o desenvolvimento. Brasília, DF: Fundação Banco do Brasil, 2004. 216 p.

LASSANCE JUNIOR, A. E. A. (Org.). Tecnologia social: uma estratégia para o desenvolvimento. Brasília, DF: Fundação Banco do Brasil, 2004.

LIPPERT, R. K. Neo-liberalism, police, and the governance of little urban things. Foucault Studies, n. 18, p. 49-65, 2014.

LOPES, R. E. et al. Oficinas de atividades com jovens da escola pública: tecnologias sociais entre educação e terapia ocupacional. Interface: Saúde, Educação, Comunicação, v. 15, n. 36, p. 277-288, 2011.

MUELlER, R. R.; FERRAZ, D. L. Crítica a uma apropriação unilateral de tecnologia: a análise do conceito de tecnologia social. Cadernos de Pesquisa Interdisciplinar em Ciências Humanas, v. 14, n. 104, p. 131-150, 2013.

MUNRO, I. The management of circulations: biopolitical variations after Foucault. International Journal of Management Reviews, v. 14, n. 3, p. 345-362, 2012.

NOVAIS, H. T.; DIAS, R. Contribuições ao marco analítico-conceitual da tecnologia social. In: DAGNINO, R. Tecnologia social: ferramenta para construir outra sociedade. Campinas, SP: Unicamp, 2009.17-54 p.

PATTON, P. Foucault's 'critique' of neoliberalism: Rawls and the genealogy of public reason. New Formations: A Journal of Culture/Theory/Politics, v. 80, n. 80, p. 39-51, 2013.

REVEL, J. Foucault and his 'other': subjectivation and displacement. In: MEZZANDRA, S.; REID, J.; SAMADDAR, R. The biopolitics of development: reading Michel Foucault in the postcolonial present. New Delhi: Springer, 2013.15-24 p.

RODRIGUES, I.; BARBIERI, J. C. A emergência da tecnologia social: revisitando o movimento da tecnologia apropriada como estratégia de desenvolvimento sustentável. Rev. Adm. Pública, v. 42, n. 6, p. 1069-1094, 2008.

SCHUMACHER, E. F. Small is beautiful: economics as if people really mattered. London: Abacus, 1973.

SILVA, A. C.; ALENCAR, M. H. B. C. Tecnologia social visando a promoção de saúde em uma comunidade rural de São Luís, MA. Saúde \& Transformação Social, v. 5, n. 1, p. 66-72, 2014.

SOFFNER, R. K. Tecnologias sociais e práxis educativa. Revista de Educação PUC-Campinas, v. 19, n. 1, p. 57-62, 2014.

SPRINGER, S. Neoliberalism as discourse: between Foucauldian political economy and Marxian poststructuralism. Critical Discourse Studies, v. 9, n. 2, p. 133-147, 2012.

VARGA, S. The politics of nation branding: collective identity and public sphere in the neoliberal state. Philosophy \& Social Criticism, v. 39, n. 8, p. 825-845, 2013.

WACQUANT, L. Três etapas para uma antropologia histórica do neoliberalismo realmente existente. Caderno CRH, v. 25, n. 66, p. 505-518, 2012. 